\title{
Research on the Supply of Rural Public Cultural Service Based on Demand of Villagers
}

\author{
Xian Zhang \\ College of Economics and Management, Yunnan Agricultural University, Kunming, 650201, China \\ Email: 280235662@qq.com
}

Keywords: Rural public culture, Public cultural, Service, Demand and supply

\begin{abstract}
Rural public cultural service is an important part of public cultural service and an important content of cultural construction. After years of efforts, rural public cultural service in China has achieved certain results, but it still cannot meet the villagers' needs in variety, pluralism and convenience. Based on the demand orientation of villagers, this paper gives the suggestions for the development of rural cultural service supply to provide some references for the relative researchers.
\end{abstract}

\section{Introduction}

Since the reform and opening for more than 30 years, with the increase of income and the improvement of living standards, the masses of villagers have increasingly strong demand for spiritual culture. Now the rural region, villagers' daily cultural needs mainly depend on television, personal computer, intelligent mobile phone and other private cultural facilities to meet the demand. Compared with the private culture of the peasants, the rural public culture is declining. Although the government has taken some measures to promote the development of rural public culture, but the effect is not obvious, the public cultural resources provided by the government are still seriously lacking. In addition, due to the rise of the feudal superstition of the peasants, the spread of various informal religious activities, rampant gambling, making some healthy and civilized forms of public culture is declining. The supply of rural public cultural services is an important part of rural governance. From the public point of view of product attributes, the supply responsibility should belong to the government, but a single government led supply mode problems of low rate and input culture cannot meet the villagers' demand and lack of investment, use of public cultural facilities, hindered the development of rural public culture. Demand orientation requires the government to attach importance to the cultural will of villagers, respect the right of expression of the cultural needs of villagers and participate in public decision-making, and construct the expression mechanism of villagers public cultural needs which is suitable for China's national conditions. At present, the government is the main provider of public cultural services in rural areas, and it has an inescapable responsibility. But the rural public culture service is not monolithic in some areas the government not to touch, some areas beyond the reach of some areas of government into efficiency is not high, and social organization in a multi-dimensional structure, the multi perspective, multi field angle and other advantages, can effectively supplement the government function and the market function of Fu ling. The government should apply the limited financial resources to the public cultural services in rural areas, which belong to pure public goods. In this process, demand orientation is an important dimension of the construction of public cultural service system.

\section{Demand Features of Rural Public Cultural Service for Villagers}

\subsection{Variety of the Demand}

Since the founding of the public cultural service system in China, the basic cultural needs of the people have been framed by the government as reading, reading newspapers, listening to the radio, watching movies and television, etc., and formed a supply mode dominated by the government 
cultural input. But now, rural public cultural service demand has already exceeded the narrow range of watch, listen and read the "old three", gradually developed into entertainment, information access, stylistic knowledge learning, skill development is one of the complex elements of the traditional system, the rural public culture service is in low efficiency and even predicament. But behind the low efficiency is the high homogenization of the content of rural public cultural service supply, which embodies the convergence and monotony in the format of project construction. At present, the rural public cultural service to the implementation of the government organization of farm house, radio and television coverage, rural film screenings and other cultural projects that benefit, but in the existing government system and the performance evaluation mechanism, political thinking and administrative logic similar to local government cultural project to express the wishes of the government, the government achievements show as the key leading to rural cultural project in different areas of design format, project content is almost the same, the larger. In recent years, the town in different administrative villages to guide and encourage the development of agriculture project economic crop planting, flower seedling cultivation, ecological breeding characteristics, villagers of walnut trees, cherry trees, cedar trees planting and breeding technology and modern agricultural products marketing knowledge had diverse needs, and the village farm house only some theoretical propaganda, the old outdated traditional crop of books, most of the village's books with both monotonic backward and highly homogeneous, seriously weakened the agricultural technology spread, drive the development of rural library function.

\subsection{Pluralism of the Demand}

The multiple subjects of rural public cultural supply are in a fragmented state, which not only fails to exert the resultant force of multiple subjects, but also causes the problems of isolated operation of rural public cultural service supply project, the fragmented content of supply, poor supply efficiency and so on. In the dimension of government subject, the rural public cultural service is at the intersection of many government departments, the lack of effective integration and coordination among departments, fragmentation phenomenon is more serious. Vertically, the Ministry of culture is the main sector that dominates the provision of public cultural services throughout the country, but at the local level, the division of these institutions varies considerably, and the power and responsibility relations between the institutions are blurred. In practice, the competent departments co-ordination is not enough, collaborative construction insufficient visible from time to time, detract from the service efficiency; on the other hand, the rural public culture service relates to culture, agriculture, education, finance and other government departments, segmentation of buildings, bull management issues outstanding, leading to supply project efficiency. In the dimension of non-government subject, which is more and more involved in the supply of rural public cultural service, which aggravates the fragmentation of the supply subject and its service supply. At present, in addition to the government's public cultural service projects, there are also some forms of public cultural service in the rural areas, such as self-organized cultural activities, social forces undertaking the theatrical performances held by government procurement projects, and entertainment performances by folk performing arts groups. In some rural areas, some backward folk beliefs by making self-organization way, disturb the order of rural culture. Secondly, in the social forces to undertake government projects to carry out the theatrical performances, because of lack of strict screening and supervision of the government body to undertake some unqualified cultural organizations or groups will swoop. The content of rural public cultural service is rich and colorful in name, but it is very serious in fact.

\subsection{Convenience of the Demand}

In rural areas, the development of economy, the accumulation of wealth and other material needs are easy to squeeze the expression and satisfaction of spiritual and cultural needs of residents, therefore, the rural public cultural services must pay attention to the convenience of demand satisfaction. This requires a reasonable mix of different ways of supply. With the rise of the online and offline hot words, we can clearly understand the problems existing in the supply mode of rural public cultural services. At present, the rural public cultural service is dominated by administrative 
led supply, and the development and utilization of online tools are insufficient and the supply mode is monotonous, which restricts the convenience of demand satisfaction. Under the online supply level, the administrative led hardware facilities construction, book distribution, literature and art to the countryside and other projects constitute the main content of rural public cultural services. But this offline supply largely reduces the convenience of villagers' public cultural service needs. On the one hand, the administrative led supply under the line has the color of "contract system" of cultural construction. The rural public culture service supply line project is often superior provisions of the action or officials of the imagination, even wishful thinking, and the government led projects are often simple and formatting, only pay attention to the official content of interest while ignoring the actual needs of the place, resulting in the line supply cannot meet the convenience requirements to meet the needs of residents even from the actual demand. On the other hand, the supply under the line is restricted by external factors, and the accessibility of service is lack of guarantee. However, at present, there are still a lot of gaps in the online supply of rural public cultural services. Only a few services involve online supply components, the degree of development and utilization is far from enough, and the degree of digitization of public cultural services is low. This makes the valuable network information resources idle in rural areas, and cannot realize the complementary gain between offline and online supply.

\section{Supply Suggestions of Rural Public Cultural Service Based on Demand of Villagers}

\subsection{Supply Diverse Cultural Service}

Only when villagers participate in the construction of rural public culture, can the quality and level of rural public cultural service be improved. Therefore, the self-sufficient supply mode of villagers is the most suitable and convenient way. For example, the government can provide free training to villagers, encourage villagers with interest and expertise to participate in public cultural activities, and use their favorite forms to improve rural public cultural knowledge, and guide the existing villagers cultural organizations. Only in this way can the villagers self-sufficiency supply their advantages and avoid disadvantages. The supply model of public welfare. The relevant legal system of rural public cultural service construction in China is still not perfect, and the development of rural cultural market is lack of strong legal protection. Such as the lack of detailed legal provisions on how to manage the bidding, taxation and management of public cultural projects in rural areas, which results in some local management confusion. Therefore, the relevant government departments should improve the relevant laws as soon as possible, and the original macro laws more detailed, the introduction of more operational laws and regulations, so that it is more in line with the real situation in rural areas. The government should give special policy support to the public cultural organizations which are helpful to promote the development of rural culture, such as infrastructure, land use and tax revenue, so as to promote their healthy development. Commercial supply model. Under the condition of socialist market economy, the enterprise is the main body of providing market cultural service. The fierce market competition will prompt the public administration organizations to pay more attention to improving the efficiency of public cultural service supply. The enterprise must participate in the construction of public cultural There are both advantages and disadvantages. Play the role of market players, adopt financial support, the government encourages enterprises to participate in some of the risk of cultural projects, but also allows enterprises to purchase a certain public cultural activity held. In this way, the public cultural service construction can be combined with the interests of enterprises to achieve a win-win situation of economic and social benefits.

\subsection{Provide Multivariate Cultural Service}

Culture is a spiritual force. If handled properly, it can be transformed into material forces, which, in turn, is beneficial to the local economic development. It can be said that in order to improve the construction of rural public culture, we must fully respect the right of expression of villagers' needs, and mobilize the enthusiasm of villagers to participate in the construction of public culture. Officials should be based on the people, not by political achievements. For a long time, the "rigid service" 
provided by the government has not been able to meet the villagers' "elastic demand", which leads to the waste of public cultural resources. The construction of rural public culture should serve the villagers, and meet the practical interests of villagers as the standard. To improve the construction of rural public cultural services, to formulate a public cultural policy in line with the real needs of villagers, and to focus on the implementation. At present, the current task of the reform of public cultural supply system is to adjust the direction of public cultural supply, and truly establish the rural public cultural service supply system oriented by villagers. Introducing social forces to construct multi cooperation system of demand orientation. At present, the cultural needs of villagers show diversified characteristics, and the government's single supply cannot meet the needs of different groups. Therefore, it is necessary to introduce social forces to build a demand oriented multi cooperation system to improve the effectiveness of rural public cultural supply. First, the government should play a leading role in the provision of rural public cultural services, especially in the field of public welfare infrastructure construction, we should adhere to the government's direct investment. We should encourage and support villagers to run their own culture, and actively develop folk cultural organizations in rural areas, especially the leading role of those who have the experience of performing arts and literature. We should improve the cultural procurement mechanism of the government, mobilize social forces to set up cultural undertakings, encourage social capital to set up cultural entities in various forms within the policy scope, so as to effectively meet the diverse cultural needs of villagers.

\subsection{Offer Convenient Cultural Service}

The combination of a series of such a system, namely in the rural public cultural products and services of rural residents in the supply and demand investigation, demand, expression of the supply of public cultural services and the participation in the process of public cultural service evaluation system as the core, combined with the ability to determine what resources supply, how supply. "Internet plus open public cultural services in rural areas of the" last mile "has become an important innovation of the current practice, but in view of rural informatization, network level, should pay extra attention to the online supply strategy, follow the" maximum utilization, the most appropriate break "principle, make full use of existing network infrastructure resources. Choose the most suitable development path of rural practical supply line. Taking the digital construction of cultural project as an opportunity, speeding up the construction process of digital Rural Library and cultural information sharing project, improving the coverage density, and promoting the network of rural public cultural services. Government and public cultural service institutions should set up the thinking of big data governance, and bring public cultural services in rural areas into the scope of big data applications. The government should actively the construction of rural culture and information database, and the establishment of cultural information sharing platform and library, museum and other Internet, based on information collection, analysis of rural public cultural service requirements, coordinate the supply of the main body, the implementation of the rural public culture service supply. We can use big data to achieve the rural public cultural service audience segmentation and service segmentation, to achieve the effect of cultural poverty alleviation precision. Strengthen the application of self-media development, digital means to communicate urban and rural public cultural services, improve the level of urban and rural integration. Libraries, cultural centers, museums and other public cultural institutions should actively develop and perfect the network client, since the number of public media application and WeChat network tool system, so that the rural residents can enjoy digital public cultural services through smart mobile phone, computer and other equipment.

\section{Conclusions}

The aim of rural public cultural construction is to provide high-quality, efficient and fair public cultural services for villagers, and to meet the public cultural demands. However, the rural areas are still the weakest link in the construction of public cultural services in china. For a long time, the contradiction between the supply of government and the demand of villagers has led to many 
problems in the construction of public cultural services in rural areas, and even once bogged down. Only by providing diversified, pluralistic and convenient cultural supply can really meet their needs.

\section{Acknowledgements}

This paper is the periodical results of the National Social Science Fund Project named "A study on the demand and supply of the villagers' public culture in the process of urban and rural integration in the western border ethnic areas" (Grant No. 14BMZ107). It is also the periodical results of the Social Sciences Fund Project of Young and Middle-Aged Talents of Yunnan Agricultural University named “Models and Mechanisms of E-commerce Poverty Alleviation in Yunnan” (Grant No. 2013PY13).

\section{References}

[1] Ren He. An Analysis of Public Cultural Services Provision in Rural China: A Case Study of Free Movies Screened for Rural Residents [J]. China Rural Survey, 2016(3): 64-70+96.

[2] Chen Jian. Transcending Structural Failure: A Study on the Supply-Side Reform of Rural Public Cultural Service [J]. 2017(9): Library Research, 37-43.

[3] A Study on Rural Public Cultural Service System under the Perspective of Demand- Based on the Survey of City B in Province H [J]. Chinese Public Administration, 2013(7): 68-73.

[4] Zhuang Huachun. Improvement of Rural Public Cultural Service System in China from the Perspective of Overall Urban-rural Development [J]. Journal of Southwest Petroleum University (Social Sciences Edition), 2017, 19(3): 32-37. 